\title{
Towards improving diagnosis of memory loss in general practice: TIMeLi diagnostic test accuracy study protocol
}

\author{
Sam T. Creavin ${ }^{1 *}$, Sarah J. Cullum¹, Judy Haworth², Lesley Wye ${ }^{1}$, Antony Bayer ${ }^{3}$, Mark Fish ${ }^{4}$, Sarah Purdy ${ }^{1}$ \\ and Yoav Ben-Shlomo'
}

\begin{abstract}
Background: People with cognitive problems, and their families, report distress and uncertainty whilst undergoing evaluation for dementia and perceive that traditional diagnostic evaluation in secondary care is insufficiently patient centred. The James Lind Alliance has prioritised research to investigate the role of primary care in supporting a more effective diagnostic pathway, and the topic is also of interest to health commissioners. However, there are very few studies that investigate the accuracy of diagnostic tests for dementia in primary care.

Methods: We will conduct a prospective diagnostic test accuracy study to evaluate the accuracy of a range of simple tests for diagnosing all-cause-dementia in symptomatic people aged over 70 years who have consulted with their general practitioner (GP). We will invite eligible people to attend a research clinic where they will undergo a range of index tests that a GP could perform in the surgery and also be assessed by a specialist in memory disorders at the same appointment. Participating GPs will request neuroimaging and blood tests and otherwise manage patients in line with their usual clinical practice. The reference standard will be the consensus judgement of three experts (neurologist, psychiatrist and geriatrician) based on information from the specialist assessment, GP records and investigations, but not including items in the index test battery. The target condition will be all-cause dementia but we will also investigate diagnostic accuracy for sub-types where possible. We will use qualitative interviews with patients and focus groups with clinicians to help us understand the acceptability and feasibility of diagnosing dementia in primary care using the tests that we are investigating.
\end{abstract}

Discussion: Our results will help clinicians decide on which tests to perform in someone where there is concern about possible dementia and inform commissioning of diagnostic pathways.

Keywords: Dementia, Primary care, General practice, Sensitivity and specificity, Diagnostic tests

\section{Background}

Dementia is a syndrome of global cognitive impairment which represents a decline from a previous level of functioning, often with behavioural and psychiatric symptoms [1], that affects around 750,000 people in the UK, of whom half have a diagnosis recorded on GP records [2]. Dementia, recently termed "major neurocognitive disorder" [3, 4], is categorised according to clinical features and presumed aetiology with the common clinical

\footnotetext{
* Correspondence: Sam.Creavin@bristol.ac.uk

'School of Social and Community Medicine, University of Bristol, 39 Whatley Road, Bristol BS8 2PS, UK

Full list of author information is available at the end of the article
}

diagnoses being Alzheimer's [5, 6], ischaemic cerebrovascular disease [7], Lewy body disease [8, 9], tauopathy/ frontotemporal dementia [10], and other rarer causes. All-cause-dementia is also defined, without additional specified clinical features needed for the subtype definitions [11-13].

In the population, Alzheimer's disease and vascular pathology are the major neuropathological features that are associated with dementia syndrome [14], but there are often multiple contributing elements [14, 15]. The association between Alzheimer's disease pathology and dementia is strongest in the young-old and weakens with age [16], leading some investigators to 
question the value of presumed aetiological diagnosis in a population where mixed pathology is usual $[17,18]$.

Mild cognitive impairment (MCI) [19] is a syndrome of cognitive impairment that is greater than expected when accounting for age and educational attainment but that does not affect activities of daily life. MCI affects between 0.1 and $42 \%$ of adults depending on which definition is used [20], and the prognosis in general practice is variable: approximately $25 \%$ of people develop dementia within three years but around $40 \%$ revert to normal [21]. Experience in clinical general practice is that when there are concerns about impaired cognition these are focussed primarily on the possibility of dementia rather than MCI, but inevitably some people who are evaluated for possible dementia will be diagnosed with MCI. In this protocol we include people who are ultimately diagnosed as having MCI when we refer to a person consulting with a GP about possible dementia (e.g. under "participants"), because it would be unusual for a person to consult a GP about possible $\mathrm{MCI}$.

People with cognitive problems and their families experience uncertainty while undergoing evaluation for possible dementia [22] and the role of primary care in supporting a more effective route to diagnosis has been identified as a priority for health research [23]. Health policy changed significantly between 2010-2015: in the USA Medicare has included an annual cognitive check-up since 2013 [24]; in England case-finding for dementia started in 2014 [25] and more recently GPs have been encouraged to take a more active role in diagnosing dementia independent of a specialist opinion [26].

Despite this change in health policy, few research studies exist to provide an evidence-based approach to the diagnosis of dementia in general practice and by GPs [27-33]. Often tests have been evaluated as tools for screening rather than diagnosis [34] and commonly used tests, such as the Montreal Cognitive Assessment (MOCA [35]) and Informant Questionnaire for Cognitive disorders in the Elderly (IQCODE [36]) have not been well evaluated in primary care $[37,38]$. GPs are uncertain about diagnosing dementia and report working collaboratively with the memory nurse over up to four consultations before reaching a diagnosis [39].

We previously found that the diagnostic accuracy of simple questions concerning functioning and independent living was comparable to longer more established measures of cognitive functioning in a group of men who had been screened for cognitive problems [40]. Here we describe a prospective study to evaluate the accuracy of a range of tests for diagnosing dementia in a primary care setting.

\section{Methods}

\section{Summary}

We will conduct a prospective diagnostic test cohort study to evaluate the accuracy of a range of index tests (detailed below) for diagnosing dementia in symptomatic adults over the age of 70 years. The primary target condition is all-cause dementia; we will also examine the diagnostic accuracy for probable Alzheimer's disease as compared to other causes of dementia. This study has been peer reviewed by the funding bodies. The background, aims and broad methods were reviewed as part of a competitive fellowship award. The funders were fully aware that over the course of the fellowship a more detailed protocol would be produced and there may be minor changes to the design in light of further work. These amendments are not re-reviewed by the funder.

\section{Participants \\ Setting}

We will conduct the study in GP practices in the Bristol, North Somerset and South Gloucestershire region, in the South West of England with a total population of 972,417 people, with $16 \%$ aged over 65 years and $11 \%$ aged over 70 years. All 54 practices in the NIHR Western Clinical Research Network (CRN) of GP practices contributing to NHS (National Health Service) research infrastructure ([41]) will be invited to take part and refer patients to the study team. Research clinics will be held in practices within the CRN selected on the basis of geographic accessibility for local participants.

\section{Recruitment}

We will include people aged 70 years and over (i.e. who have had their $70^{\text {th }}$ birthday) where concerns have been raised in the community about the possibility of dementia by the patient or others (including GP), but in whom the diagnosis has yet to be confirmed. The symptoms must have been present for at least six months and been gradual in onset and progression. We will exclude people with clinical "red-flags": co-incident tremor, weakness or dysphasia; existing diseases listed in Table 1; mental health problems needing secondary care input;

Table 1 Conditions resulting in exclusion from TIMeLi study

Prior diagnosis of a parkinsonian condition (including

Parkinson's disease)

Multiple sclerosis

Learning disability

Motor neuron disease

Huntington's disease

Registered blind

Severe hearing impairment (operationalised as unable to use telephone) 
terminal illness; or inability to attend research clinic with an informant. People with these conditions will almost always need specialist input to make a diagnosis of dementia, and an informant history is required for a robust diagnosis of dementia. Additionally we will exclude people with severe dementia (operationalised as lack of capacity to consent) as diagnosis in this group is less challenging.

Figure 1 outlines the process of the study. GPs will pass details on potential participants, after participant consent, to the research study by completing a template form that is then emailed to a secure nhs.net email address [42]. At the time of referral, the GPs are asked to state their prior belief ("gut feeling") concerning the diagnosis and their confidence in this diagnosis (see "test methods | index tests" below for more detail). No prior testing is required to determine eligibility for the study, the only requirements are listed in the inclusion and exclusion criteria above. Investigations such as blood tests and neuroimaging will be requested by the GP in line with their usual clinical practice and can be conducted in parallel with attendance at the study clinic as the results will not be available to the researcher at the clinic. An administrator will process forms from the GP so that the researcher's clinical evaluation of participants is blinded to the GP judgement, and this will only be made available to the study team at the analysis stage.

\section{Sampling}

The eligible study population will be defined by a consecutive series of patients who meet the criteria for recruitment, but we recognise that not everybody who is eligible will participate. Table 2 shows some of the reasons for non-participation of eligible patients and how we will try to minimise bias.

A particular problem is that GPs might not mention the study to people who are eligible because they forget to do so. To address this we will use an electronic prompt within the electronic medical record. Figure 2 outlines the computer prompts that are triggered when the GP enters a problem heading related to memory problems or cognitive difficulties during the consultation with the patient.

The computer prompts will help us to monitor practices for potentially eligible patients who have not participated using electronic searches of coded data in the electronic medical record.

\section{Data collection}

Research clinics will be held in GP practices in the NIHR Western CRN. At the research clinic one GP research doctor (STC) will see one patient-informant dyad for the index tests and simultaneously a dementia specialist doctor $(\mathrm{JH})$ will see a different participant dyad for the specialist assessment of up to one hour in a separate room. Participants will have a 10-min rest before crossing over to see the other doctor and will be at the clinic for approximately $2.5 \mathrm{~h}$ in total. We aim that half of participants will see each doctor first, but the order of consultations will be determined by patient availability for appointments. So that the index tests and specialist assessment are conducted independently

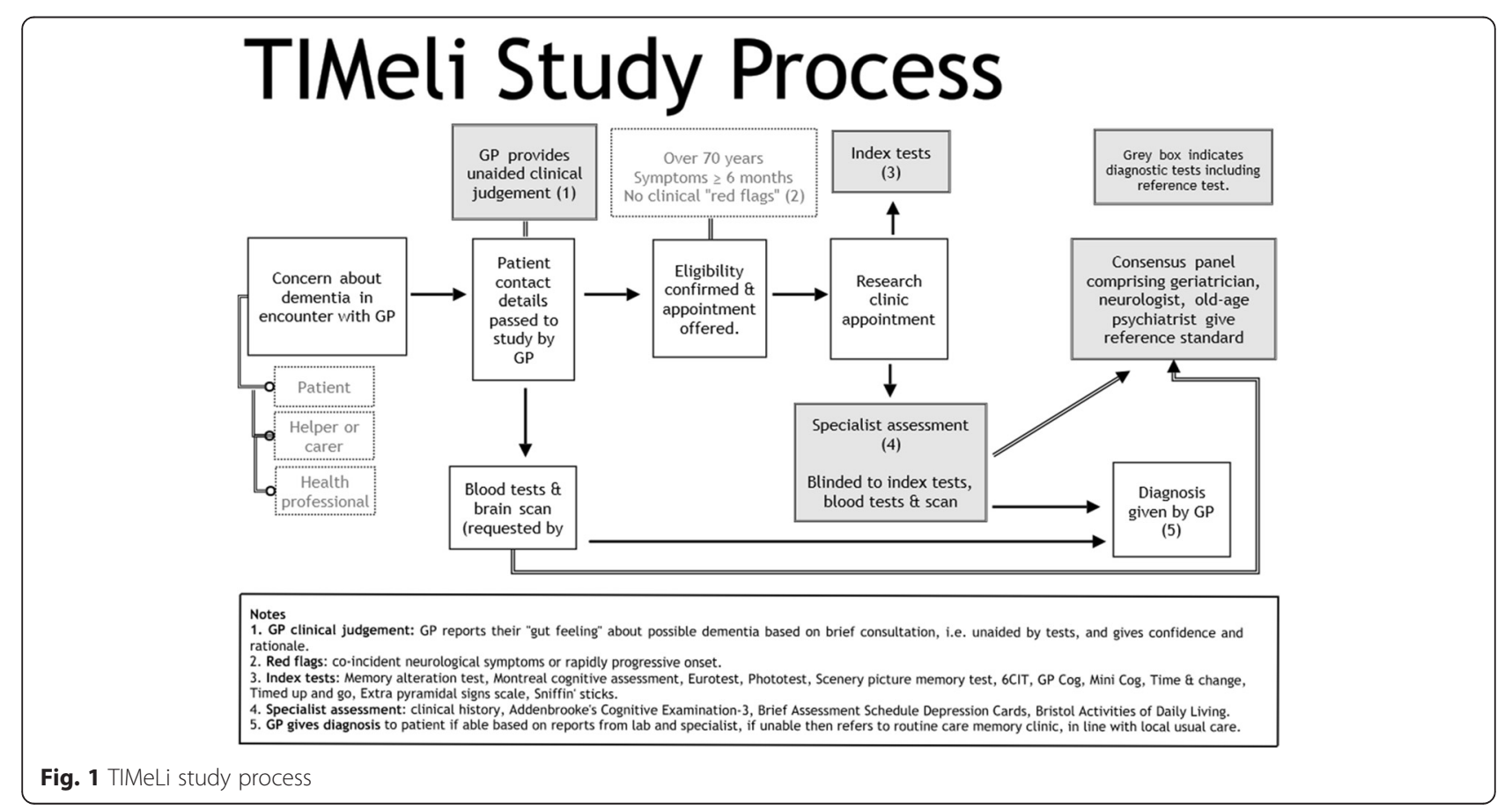


Table 2 Possible reasons for non-participation of eligible patients

\begin{tabular}{ll}
\hline Potential barrier to recruitment & How we will address this \\
\hline $\begin{array}{l}\text { GP factors } \\
\text { Not thinking of the study } \\
\text { when it is relevant }\end{array}$ & $\begin{array}{l}\text { Computer prompts when relevant } \\
\text { problem code entered }\end{array}$ \\
$\begin{array}{l}\text { Being too busy to discuss } \\
\text { it with patients }\end{array}$ & $\begin{array}{l}\text { Computer prompt to record this } \\
\text { Believing that a patient is } \\
\text { not suitable }\end{array}$ \\
$\begin{array}{ll}\text { Patient factors } & \text { Computer prompt to record this } \\
\text { Difficulty accessing research } \\
\text { clinic [day, time, travel] }\end{array}$ & $\begin{array}{l}\text { Provide transport if needed, range of } \\
\text { Clinics on different days and times }\end{array}$ \\
Other health issues & $\begin{array}{l}\text { Allow people to rearrange appointment } \\
\text { if needed }\end{array}$ \\
Wanting time to decide & $\begin{array}{l}\text { Allow people time to think and call } \\
\text { back }\end{array}$ \\
No clear reason but declined & $\begin{array}{l}\text { Computer prompt to record study } \\
\text { declined }\end{array}$ \\
\hline
\end{tabular}

of investigations, test results will be electronically extracted by the study team at the end of the study, and will not be available on the day of the research clinic, though they will be available to inform the reference standard. We planned data collection and analysis in advance.

\section{Test methods}

\section{Index tests}

GPs often use heuristics when making diagnoses [43-45], including the possibility of dementia [46, 47]. Referring GPs will be asked to give their "gut feeling" about the possibility of dementia, based on their brief interaction with the patient during the consultation at the time of referral. We will ask GPs to report whether they think the person has dementia, cognitive impairment (but not dementia), or is cognitively normal. In addition they are asked to rate their diagnostic confidence using a $10 \mathrm{~cm}$ visual analogue scale which is then converted to a percentage (prior probability) and their rationale for their opinion.
In deciding what simple index tests should be evaluated, we reviewed the literature to identify cognitive tests and also referred to a guide to clinicians about tests that could be used in primary care [48]. We selected tests for the index battery on the basis of the following criteria:

1. Available to use for free - i.e. not copyright (therefore MMSE [49] excluded);

2. Previously evaluated in a primary care setting in at least one study;

3. Not been evaluated in primary care before but conceptually of interest (Timed up and go; Sniffin' sticks).

Based on these criteria we selected studies with good diagnostic accuracy (Youden index [50] of greater than 0.75 or a sensitivity or specificity of greater than 0.85 at the optimal reported threshold) and judged the studies diagnostic accuracy against the time taken to conduct the test, favouring brief tests with high specificity. On this basis the following tests ("index battery") were selected to be included in the index battery: Memory alteration test (M@T, [51]), Eurotest [27], Phototest [52], Scenery picture memory test [53], 6CIT [54], GPCOG [55], Mini-Cog [56], Time and change [57], Timed upand-go [58], Extra pyramidal signs scale [59], Sniffin' sticks [60,61]. We also included assessments of activities of daily living; the Pfeffer [62], Lawton [63] Katz [64], AD8 [65] and Informant questionnaire for cognitive disorders in the elderly (IQCODE) short version [36]. A different group of investigators have reviewed the use of cognitive tests in primary care [66], compared to the tests identified by that group our battery does not include memory impairment screen (MIS) [67] or abbreviated mental test (AMT) [68] but does include indicators which reflect similar aspects of cognitive testing and are possibly more culturally fair, and which have fewer restrictions on use. In the MIS (all rights reserved), patients are asked to read from a list of four words, then engaged in a distractor activity and finally scored on free

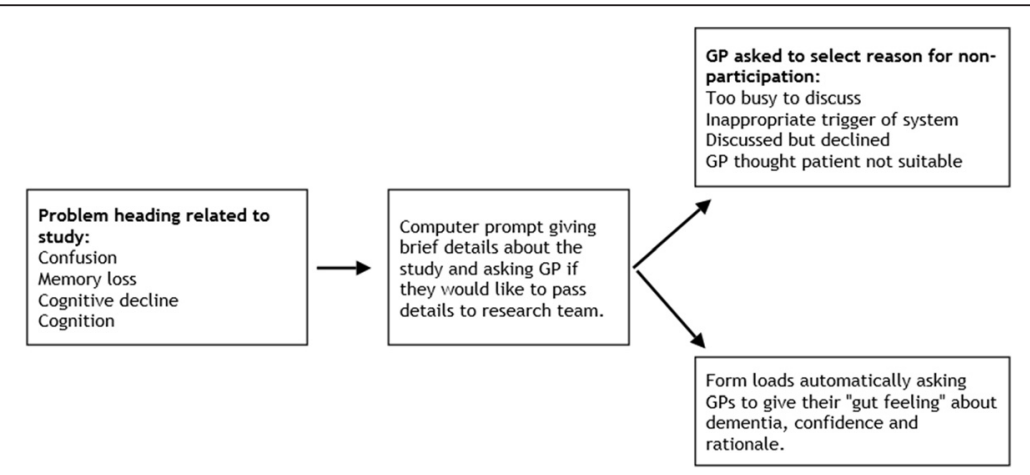

Fig. 2 Computer prompts to aid participation 
and cued recall; in comparison Phototest (which is available for use under a creative commons license [69]) requires participants to identify six photos, perform a distractor task and then tests free and cued recall. We include six of the 10 items in the AMT in our index battery and exclude age and recognition of two people (which are arguably less discriminative in people without severe impairment) year of First World War and name of present monarch (which are arguably more culturally determined).

We did not initially include the Montreal Cognitive Assessment (MoCA, [35]) in the index battery as it was originally designed to diagnose or identify $\mathrm{MCI}$, had been advocated for use in secondary care [48] and had not been investigated in primary care [38]. However, we revised our protocol in light of subsequent policy changes in 2015 that encouraged GPs to diagnose dementia in typical situations without referring to a specialist [26] using the MoCA as the preferred instrument. We replaced the M@T with the MoCA because we judged that including both the MoCA and the M@T would be overly burdensome for participants and have little added value.

Index tests will be performed as instructed by the original authors by a single doctor who has completed postgraduate training in general practice (STC), who will not be aware of any other clinical information about the participants, including the GPs "gut feeling" about the possibly of dementia. The full index battery takes around $25 \mathrm{~min}$ in a healthy person and around $50 \mathrm{~min}$ in a person with dementia.

\section{Specialist assessment}

A single dementia specialist $(\mathrm{JH})$ will perform a standardised clinical evaluation lasting approximately an hour, comprising clinical history, the Addenbrooke's Cognitive Examination third edition (ACE-III) [70], Brief Assessment Schedule Depression Cards (BASDEC) [71] and the Bristol activities of daily living questionnaire (BADL) [72]. The specialist will not have access to any investigation results because we want to assess the accuracy of clinical assessment by a specialist. If the specialist considers that further investigations and assessment are needed to exclude a rare dementia aetiology we will suggest to the referring GP that they may wish to refer the patient to the National Health Service (NHS) memory clinic. The specialist will be asked to reach a clinical judgement about the cognitive status of participants operationalised as normal, cognitive impairment, or dementia, as well as the most likely aetiology of the dementia based on the information available to them.

\section{Reference standard}

The reference standard will be the consensus judgement by an expert panel about the diagnosis of dementia, using information from the specialist assessment, blood tests, neuroimaging, and medical records (where needed). Information from the index battery and GP "gut feeling" will not contribute to the reference standard. We will allow the reference panel access to the results of any tests that have been conducted up to six months after a research clinic because in some cases special tests such as regional cerebral blood flow single photon emission computed tomography (SPECT) or dopamine transporter imaging (DAT) scans may have been requested and would help refine the reference standard. We will use a stepwise-reveal process for all items that contribute to the reference panel, starting with the anonymised demographics, medical history and clinical assessment from the research clinic, followed by blood tests and routine neuroimaging such as plain computed tomogram $(\mathrm{CT})$ or plain magnetic resonance imaging (MRI), followed by additional information from medical records and additional tests such as DAT or SPECT scans or neuropsychology results (if available). We intend to use a staged decision making approach for assigning the final diagnosis [73] where each expert initially assigns a diagnosis independently and then discordant cases are discussed.

\section{Definitions}

To account for differences between definitions [74] we will apply three different criteria for dementia: Diagnostic and Statistical Manual of Mental Disorders (DSM) IV [12], DSM 5 [3] and the International Classification of Diseases Tenth edition (ICD 10 [11]). For cognitive impairment that does not meet criteria for dementia we will use two definitions: DSM 5 [3] mild neurocognitive disorder and Peterson MCI [19]. The final reference standard for the main analysis will be the consensus judgement about the presence or absence of dementia, cognitive impairment or normal cognition, based on the application of the three definitions above. An example of how we might assign diagnoses is in Table 3.

We will also investigate how the prevalence of $\mathrm{MCI}$ and dementia, and the accuracy of tests for diagnosis, varies with the three different definitions. We will then define subtypes of dementia according to standard definitions: Alzheimer's disease [6], vascular [7], frontotemporal [10] and Lewy body [9].

\section{Follow-up}

We will follow consenting participants electronically using their GP records for up to seven years to determine whether those who do not have dementia at baseline develop it later on, and whether participants who are identified as having dementia by the study specialist assessment subsequently have their diagnosis refined. We will use follow-up data to analyse the diagnostic accuracy of tests for the diagnosis of dementia in the 
Table 3 Example of process for assigning the reference standard

\begin{tabular}{|c|c|c|c|}
\hline Assessor & $A B$ & MF & SJC \\
\hline Role & $\begin{array}{l}\text { Consultant geriatrician with interest in } \\
\text { memory disorders }\end{array}$ & Consultant neurologist & $\begin{array}{l}\text { Consultant old age } \\
\text { psychiatrist }\end{array}$ \\
\hline Study ID & $\mathrm{XX1}$ & $\mathrm{XX1}$ & $\mathrm{XX1}$ \\
\hline \multicolumn{4}{|c|}{ Status: Dementia/major neurocognitive disorder DSM 5 or MCI [19]/mild neurocognitive disorder DSM 5 or Normal } \\
\hline DSM ${ }^{a}$ IV [12] & Dementia & Dementia & Dementia \\
\hline $\mathrm{DSM}^{\mathrm{a}} 5$ [13] & Major neurocognitive disorder & $\begin{array}{l}\text { Mild neurocognitive } \\
\text { disorder }\end{array}$ & $\begin{array}{l}\text { Major neurocognitive } \\
\text { disorder }\end{array}$ \\
\hline ICD $10^{\mathrm{b}}[11]$ & $\mathrm{MCl}$ & Dementia & Dementia \\
\hline Overall & Dementia & Dementia & Dementia \\
\hline Consensus judgement & Dementia & & \\
\hline \multicolumn{4}{|l|}{ Aetiological subtype } \\
\hline Alzheimer's disease probable [6] & $x$ & & $x$ \\
\hline Alzheimer's disease possible [6] & & $x$ & \\
\hline \multicolumn{4}{|c|}{$\begin{array}{l}\text { Ischaemic cerebrovascular disease dementia } \\
\text { probable [7] }\end{array}$} \\
\hline \multicolumn{4}{|c|}{$\begin{array}{l}\text { Ischaemic cerebrovascular disease dementia } \\
\text { possible [7] }\end{array}$} \\
\hline \multicolumn{4}{|l|}{ Mixed aetiology [13] } \\
\hline \multicolumn{4}{|l|}{ Parkinson's [13] } \\
\hline \multicolumn{4}{|c|}{ Lewy Body Dementia probable $[8,9,13]$} \\
\hline \multicolumn{4}{|c|}{ Lewy Body Dementia possible $[8,9,13]$} \\
\hline \multicolumn{4}{|c|}{ Tauopathy/Frontotemporal dementia [10] } \\
\hline \multicolumn{4}{|l|}{ Other (describe) [13] } \\
\hline \multicolumn{4}{|l|}{ Uncertain [13] } \\
\hline Consensus judgement & Alzheimer's disease probable [6] & & \\
\hline
\end{tabular}

Notes: For the main analysis participant XX1 would be classed as having dementia aDiagnostic and statistical manual of mental disorders/

binternational classification of diseases

future ("delayed verification") but the reference standard for the cross-sectional diagnosis of dementia will not take account of information that occurred more than six months subsequent to the research clinic.

\section{Statistical methods}

\section{Sample size}

Table 4 shows the sample size required for a given lower $95 \%$ confidence interval (LCI) based on a specificity of $95 \%$ and a prevalence of dementia of $75 \%$.

Table 4 Sample size for diagnostic test accuracy study, assuming specificity of $95 \%$ and prevalence of dementia of $75 \%$

\begin{tabular}{llll}
\hline $\begin{array}{l}\text { Lower 95 \% } \\
\text { confidence } \\
\text { interval of } \\
\text { specificity }\end{array}$ & $\begin{array}{l}\text { Number of healthy } \\
\text { people needed for } \\
\text { lower confidence } \\
\text { interval }\end{array}$ & $\begin{array}{l}\text { Number of people } \\
\text { with dementia needed } \\
\text { for lower confidence } \\
\text { interval }\end{array}$ & $\begin{array}{l}\text { Total } \\
\text { sample } \\
\text { size }\end{array}$ \\
\hline $85 \%$ & 93 & 279 & 372 \\
$80 \%$ & 50 & 150 & 200 \\
$75 \%$ & 34 & 102 & 136 \\
\hline
\end{tabular}

We used standard tables for the sample size calculation [75].

Other investigators have reported a specificity of between $89 \%$ [29] and 94 \% [76] for unaided "gut feeling" of GPs for diagnosing dementia, and individual tests such as clock draw (specificity $96 \%$ [33]), Timed up-and-go (specificity $89 \%$ [33]) and Phototest (specificity $89 \%$ [52]) also have high specificity. We aim to recruit a sample of between 200-300 people. Using the five events per variable rule [77] this would allow us to evaluate between 30 and 45 diagnostic indicators (at $75 \%$ prevalence of dementia).

\section{Analysis}

The plan for analysis may change with methodological advances in diagnostic science, but the current plan is outlined. We will construct $2 \times 2$ tables for each diagnostic indicator in the index battery and the outcome dementia, as defined by the consensus panel. We will also evaluate the discriminative ability of diagnostic indicators by calculating the area under the curve. 
We will use logistic regression models with the target condition (dementia) as defined by the consensus panel being the binary dependent variable, and the diagnostic indicators as the independent variable. We will only include diagnostic indicators that have a $\mathrm{p}$ value of less than 0.10 in univariable logistic regression in the multivariable analysis. When we perform multivariable analysis we will include diagnostic indicators in the order in which they would be performed in clinical practice, for example age and sex (if significant), followed by GP "gut feeling" (if significant) followed by any tests in the index battery (ordered by mean average time taken to perform test). This will allow us to calculate the diagnostic accuracy of (e.g.) "gut feeling" allowing for the contribution of age and sex. We will calculate standard measures of diagnostic accuracy (sensitivity, specificity, likelihood ratios, area under the curve and predictive values) together with $95 \%$ confidence intervals. We will use the regression coefficients to calculate predicted risks of dementia in participants and compare these to the actual risk using goodness of fit tests [78]. We will also consider analysing decision curves and evaluating the net reclassification index and integrated discrimination index [79].

Missing values will be imputed using multiple imputation by chained equations [80, 81]. We will perform a bootstrapping procedure to validate the final model and shrink the regression parameters [82]. We will use the model to construct a diagnostic algorithm and decision rule for use in clinical practice.

\section{Qualitative evaluation of acceptability and feasibility}

We will use joint interviews with a subsample of approximately 30 patients and their carers who attended a research clinic to determine how acceptability they would find a GP based diagnosis of dementia. The interview will be conducted after the research clinic. Participants will be purposefully sampled on the characteristics of age and GP practice (as a measure of deprivation and experience of general practice). We will not select people based on their diagnosis as this will not be known to the researcher at the research clinic. We will not offer participation when the researchers considers this would be burdensome for participants and their informants, and that this means that people with more severe cognitive impairment are unlikely to participate. Interviews will continue until saturation is reached. The topic guide will explore participants' experience of seeing their GP about possible dementia, and then ask questions about the acceptability and perceived benefits and disadvantages of a GP based diagnosis of dementia. We will use focus groups with clinicians and managers in approximately five local general practices to identify the feasibility and barriers to a diagnostic evaluation for dementia taking place in general practice.

\section{Discussion}

The TIMeLi study will be the first study, to our knowledge, to prospectively evaluate the diagnostic accuracy of a range of indicators in symptomatic people in primary care. The particular strengths of the study are the range of index tests that will be evaluated and the ability to account for the "gut feeling" of GPs. In addition, the study is being conducted in primary care with testing being delivered by a GP.

We anticipate our results will help address uncertainty about what tests are most useful to a GP to evaluate someone for possible dementia. If we identify a set of tests or diagnostic algorithm with high accuracy for diagnosing dementia then individual GPs could apply this in their clinical practice. Subsequent further work to evaluate this could lead to some people with established dementia being evaluated and diagnosed entirely in primary care, without specialist input. This does not preclude the use of neuroimaging, to help determine the likely aetiology of the dementia or to exclude alternative diagnoses, or the role of specialists for younger patients, more complex scenarios, or to provide aetiological diagnosis. Our results will inform the diagnostic approach to patients with possible dementia in primary care.

\section{Abbreviations \\ BASDEC, Brief Assessment Schedule Depression Cards; CRN, Clinical Research Network; CT, computed tomogram; DAT, dopamine transporter imaging; DSM, diagnostic and statistical manual of mental disorders; GP, general practitioner; ICD, International classification of diseases tenth edition; IQCODE, informant questionnaire for cognitive disorders in the elderly; LCl, lower confidence interval; M@T, memory alteration test; MMSE, mini mental state examination; MOCA, Montreal Cognitive Assessment; MRI, magnetic resonance imaging; NHS, National Health Service; NIHR, National Institute for Health Research; SPECT, single photon emission computed tomography; UK, United Kingdom; USA, United States of America}

\section{Acknowledgements}

Not applicable.

\section{Funding}

Sam Creavin is funded by a Wellcome Trust Research Training Fellowship 108804/Z/15/Z; £321,248.

The TIMeLi study is also funded by Avon Primary Care Research Collaboration £19,705; The Claire Wand Fund £5040; NIHR School for Primary Care Research $£ 9971$.

\section{Availability of data and material}

Our intended policy is that the team should have exclusive use of the data for a period of 24 months after the study has ended, or until the data is published. We reserve the right to retain exclusive access to the data as necessary until we have validated and disseminated our novel findings. Data will be available through the data.bris repository, published under a permissive re-use license. Users of the data who are external to the research team will be required to sign a data-sharing agreement that will specifically prohibit any attempt to (a) identify study participants or (b) attempt to contact study participants. We reserve the right to impose additional restrictions.

\section{Authors' contributions}

STC conceived and designed study; acquired funding; will acquire, analyse and interpret data. SJC help design the study; helped with acquiring funding; supervised the data collection and advised on data interpretation. JH helped with data acquisition. LW help design the study; helped with acquiring funding; supervised the data collection and advised on data interpretation. AB help with 
analysing and interpreting data. MF help with analysing and interpreting data. SP help design the study; helped with acquiring funding; supervised the data collection and advised on the statistical analysis plan and data interpretation. YBS help design the study; helped with acquiring funding; supervised the data collection and advised on the statistical analysis plan and data interpretation. All authors read and approved the final manuscript.

\section{Authors' information}

Not applicable.

\section{Competing interests}

The authors declare that they have no competing interests.

\section{Consent for publication}

Not applicable.

\section{Ethics approval and consent to participate}

All participants will provide written informed consent. This study has received a favourable ethical approval from the UK Health Research Authority Bromley Research Ethics Committee reference 14/LO/2025 and will be conducted in line with the Helsinki declaration.

\section{Author details}

'School of Social and Community Medicine, University of Bristol, 39 Whatley Road, Bristol BS8 2PS, UK. 'North Bristol NHS Trust Southmead Hospital, Southmead Road, Westbury-on-Trym, Bristol BS10 5NB, UK. ${ }^{3}$ Division of Population Medicine, Cardiff University School of Medicine University Hospital Llandough, Penarth CF64 2XX, UK. ${ }^{4}$ Department of Neurology, Musgrove Park Hospital, Taunton, Somerset TA1 5DA, UK.

Received: 3 May 2016 Accepted: 20 June 2016

Published online: 19 July 2016

\section{References}

1. Dementia: The NICE -SCIE Guideline on Supporting People with Dementia and Their Carers in Health and Social Care. National Clinical Practice Guideline Number 42. London: National Institute for Health and Care Excellence; 2011.

2. Parkin E, Baker C. Dementia - An Overview of Policy and Services, and Statistics on Prevalence. London: House of commons library; 2015. Available at http://researchbriefings.files.parliament.uk/documents/SN07007/SN07007.pdf.

3. American Psychiatric Association. Diagnostic and Statistical Manual of Mental Disorders. Fifthth ed. Arlington: American Psychiatric Association; 2013.

4. Blazer D. Neurocognitive disorders in DSM-5. Am J Psychiatry. 2013;170:585-7.

5. McKhann G, Drachman D, Folstein M, Katzman R, Price D, Stadlan EM. Clinical diagnosis of Alzheimer's disease: report of the NINCDS-ADRDA Work Group under the auspices of Department of Health and Human Services Task Force on Alzheimer's Disease. Neurology. 1984;34:939-44.

6. McKhann GM, Knopman DS, Chertkow H, Hyman BT, Jack CR, Kawas CH, Klunk WE, Koroshetz WJ, Manly JJ, Mayeux R, Mohs RC, Morris JC, Rossor MN, Scheltens P, Carrillo MC, Thies B, Weintraub S, Phelps CH. The diagnosis of dementia due to Alzheimer's disease: recommendations from the National Institute on Aging-Alzheimer's Association workgroups on diagnostic guidelines for Alzheimer's disease. Alzheimers Dement. 2011; 7:263-9.

7. Román GC, Tatemichi TK, Erkinjuntti T, Cummings JL, Masdeu JC, Garcia JH, Amaducci L, Orgogozo JM, Brun A, Hofman A. Vascular dementia: diagnostic criteria for research studies. Report of the NINDS-AIREN International Workshop. Neurology. 1993:43:250-60.

8. McKeith IG, Galasko D, Kosaka K, Perry EK, Dickson DW, Hansen LA, Salmon DP, Lowe J, Mirra SS, Byrne EJ, Lennox G, Quinn NP, Edwardson JA, Ince PG, Bergeron C, Burns A, Miller BL, Lovestone S, Collerton D, Jansen EN, Ballard CG, de Vos RA, Wilcock GK, Jellinger KA, Perry RH. Consensus guidelines for the clinical and pathologic diagnosis of dementia with Lewy bodies (DLB): report of the consortium on DLB international workshop. Neurology. 1996:47:1113-24.

9. McKeith IG, Dickson DW, Lowe J, Emre M, O'Brien JT, Feldman H, Cummings J, Duda JE, Lippa C, Perry EK, Aarsland D, Arai H, Ballard CG, Boeve B, Burn DJ, Costa D, Del Ser T, Dubois B, Galasko D, Gauthier S, Goetz CG, GomezTortosa E, Halliday G, Hansen LA, Hardy J, Iwatsubo T, Kalaria RN, Kaufer D, Kenny RA, Korczyn A, et al. Diagnosis and management of dementia with
Lewy bodies: third report of the DLB Consortium. Neurology. 2005;65: 1863-72.

10. Neary D, Brun A, Englund B, Gustafson L, Passant U, Mann D, Snowden J. Clinical and neuropathological criteria for frontotemporal dementia. The Lund and Manchester Groups. J Neurol Neurosurg Psychiatry. 1994; 57:416-8.

11. World Health Organization. The ICD-10 Classification of Mental and Behavioural Disorders: Diagnostic Criteria for Research. Geneva: World Health Organisation; 1993.

12. American psychiatric Association. Diagnostic and Statistical Manual of Mental Disorders. Fourthth ed. Washington: American psychiatric Association; 1994

13. American psychiatric Association. Diagnostic and Statistical Manual of Mental Disorders. Fourth TR. Arlington: American Psychiatric Association; 2000.

14. Neuropathology Group. Medical Research Council Cognitive Function and Aging Study. Pathological correlates of late-onset dementia in a multicentre, community-based population in England and Wales. Neuropathology Group of the Medical Research Council Cognitive Function and Ageing Study (MRC CFAS). Lancet. 2001;357:169-75.

15. Matthews FE, Brayne C, Lowe J, McKeith I, Wharton SB, Ince P. Epidemiological pathology of dementia: attributable-risks at death in the Medical Research Council Cognitive Function and Ageing Study. PLoS Med. 2009;6:e1000180.

16. Savva GM, Wharton SB, Ince PG, Forster G, Matthews FE, Brayne C. Age, neuropathology, and dementia. N Engl J Med. 2009;360:2302-9.

17. Richards M, Brayne C. What do we mean by Alzheimer's disease? BMJ. 2010:341:c4670.

18. Brayne C, Davis D. Making Alzheimer's and dementia research fit for populations. Lancet. 2012:380:1441-3.

19. Petersen RC. Mild cognitive impairment as a diagnostic entity. In J Intern Med Volume. 2004:256:183-94.

20. Stephan BCM, Matthews FE, McKeith IG, Bond J, Brayne C. Early cognitive change in the general population: how do different definitions work? J Am Geriatr Soc. 2007;55:1534-40.

21. Kaduszkiewicz H, Eisele M, Wiese B, Prokein J, Luppa M, Luck T, Jessen F, Bickel H, Mösch E, Pentzek M, Fuchs A, Eifflaender-Gorfer S, Weyerer S, König $\mathrm{H}-\mathrm{H}$, Brettschneider $\mathrm{C}$, van den Bussche $\mathrm{H}$, Maier W, Scherer $\mathrm{M}$, Riedel-Heller SG. Prognosis of mild cognitive impairment in general practice: results of the German AgeCoDe study. Ann Fam Med. 2014;12:158-65.

22. Manthorpe J, Samsi K, Campbell S, Abley C, Keady J, Bond J, Watts S, Robinson L, Warner J, lliffe S. From forgetfulness to dementia: clinical and commissioning implications of diagnostic experiences. Br J Gen Pract. 2013;63:e69-75.

23. Alzheimer's Society. Outcomes of the James Lind Alliance Dementia Priority Setting Partnership. London: Alzheimers society; 2013. Available at https://www.alzheimers.org.uk/site/scripts/download_info.php?filelD=2226

24. Cordell CB, Borson S, Boustani M, Chodosh J, Reuben D, Verghese J, Thies W. Fried LB. Alzheimer's Association recommendations for operationalizing the detection of cognitive impairment during the Medicare Annual Wellness Visit in a primary care setting. Alzheimers Dement. 2013;9:141-50.

25. Brunet MD, McCartney M, Heath I, Tomlinson J, Gordon P, Cosgrove J, Deveson P, Gordon S, Marciano S-A, Colvin D, Sayer M, Silverman R, Bhattia N. There is no evidence base for proposed dementia screening. BMJ. 2012;345:e8588.

26. Burns A, Twomey P, Barrett E, Harwood D, Cartmell N, Cohen D, Findlay D, Gupta S, Twomey C. Dementia Diagnosis and Management A Brief Pragmatic Resource for General Practitioners. 2015.

27. Carnero-Pardo C, Gurpegui M, Sanchez-Cantalejo E, Frank A, Mola S, Barquero MS, Montoro-Rios MT. Diagnostic accuracy of the Eurotest for dementia: a naturalistic, multicenter phase II study. BMC Neurol. 2006;6:15.

28. Valcour VG, Masaki KH, Curb JD, Blanchette PL. The detection of dementia in the primary care setting. Arch Intern Med. 2000;160:2964-8.

29. Pond CD, Mant A, Kehoe L, Hewitt H, Brodaty H. General practitioner diagnosis of depression and dementia in the elderly: can academic detailing make a difference? Fam Pract. 1994;11:141-7.

30. Pond CD, Mate KE, Phillips J, Stocks NP, Magin PJ, Weaver N, Brodaty $\mathrm{H}$. Predictors of agreement between general practitioner detection of dementia and the revised Cambridge Cognitive Assessment (CAMCOG-R). Int Psychogeriatr. 2013;25:1639-47. 
31. van Hout HPJ, Vernooij-Dassen MJFM, Hoefnagels WHL, Kuin Y, Stalman WAB, Moons KGM, Grol RPTM. Dementia: predictors of diagnostic accuracy and the contribution of diagnostic recommendations. J Fam Pract. 2002;51:693-9.

32. Pentzek M, Wollny A, Wiese B, Jessen F, Haller F, Maier W, Riedel-Heller SG, Angermeyer MC, Bickel H, Mösch E, Weyerer S, Werle J, Bachmann C, Zimmermann T, van den Bussche $\mathrm{H}$, Abholz $\mathrm{H}-\mathrm{H}$, Fuchs A. Apart from nihilism and stigma: what influences general practitioners' accuracy in identifying incident dementia? Am J Geriatr Psychiatry. 2009;17:965-75.

33. De Lepeleire J, Heyrman J, Baro F, Buntinx F. A combination of tests for the diagnosis of dementia had a significant diagnostic value. J Clin Epidemiol. 2005;58:217-25

34. Brown J. The use and misuse of short cognitive tests in the diagnosis of dementia. J Neurol Neurosurg Psychiatry. 2014;86(6):680-685.

35. Nasreddine ZS, Phillips NA, Bédirian V, Charbonneau S, Whitehead V, Collin I, Cummings $J$, Chertkow $\mathrm{H}$. The Montreal Cognitive Assessment, MoCA: a brief screening tool for mild cognitive impairment. J Am Geriatr Soc. 2005;53:695-9.

36. Jorm AF. A short form of the Informant Questionnaire on Cognitive Decline in the Elderly (IQCODE): development and cross-validation. Psychol Med. 1994;24:145-53.

37. Harrison JK, Fearon P, Noel-Storr AH, McShane R, Stott DJ, Quinn TJ. Informant Questionnaire on Cognitive Decline in the Elderly (IQCODE) for the diagnosis of dementia within a general practice (primary care) setting. Cochrane Database Syst Rev. 2014;7:CD010771.

38. Davis DH, Creavin ST, Yip JL, Noel-Storr AH, Brayne C, Cullum S. Montreal Cognitive Assessment for the diagnosis of Alzheimer's disease and other dementias. Cochrane Database Syst Rev. 2015;10:CD010775.

39. Dodd E, Cheston R, Fear T, Brown E, Fox C, Morley C, Jefferies R, Gray R. An evaluation of primary care led dementia diagnostic services in Bristol. BMC Health Serv Res. 2014;14:592.

40. Creavin S, Fish M, Gallacher J, Bayer A, Ben-Shlomo Y. Clinical history for diagnosis of dementia in men: Caerphilly Prospective Study. Br J Gen Pract. 2015;65:e489-99.

41. Darbyshire JH. The UK Clinical Research Network-building a world-class infrastructure for clinical research. Rheumatology (Oxford). 2008:47:745.

42. NHSmail — Health and Social Care Information Centre [http://systems.hscic. gov.uk/nhsmail]

43. Stolper E, Van de Wiel M, Van Royen P, Van Bokhoven M, Van der Weijden $T$, Dinant GJ. Gut feelings as a third track in general practitioners' diagnostic reasoning. J Gen Intern Med. 2011;26:197-203.

44. Woolley A, Kostopoulou O. Clinical intuition in family medicine: More than first impressions. Ann Fam Med. 2013;11:60-6.

45. Elstein AS, Schwartz A, Schwarz A. Clinical problem solving and diagnostic decision making: selective review of the cognitive literature. BMJ. 2002; 324:729-32

46. O'Connor DW, Fertig A, Grande MJ, Hyde JB, Perry JR, Roland MO, Silverman JD, Wraight SK. Dementia in general practice: the practical consequences of a more positive approach to diagnosis. Br J Gen Pract. 1993;43:185-8.

47. Pentzek M, Fuchs A, Wiese B, Cvetanovska-Pllashniku G, Haller F, Maier W, Riedel-Heller SG, Angermeyer MC, Bickel H, Mösch E, Weyerer S, Werle J, van den Bussche H, Eisele M, Kaduszkiewicz H. General practitioners' judgment of their elderly patients' cognitive status. J Gen Intern Med. 2009;24:1314-7.

48. Alzheimer's Society. Helping You to Assess Cognition: A Practical Toolkit for Clinicians. London: Alzheimer's Society; 2013.

49. Folstein MF, Folstein SE, McHugh PR. "Mini-mental state". A practical method for grading the cognitive state of patients for the clinician. J Psychiatr Res. 1975;12:189-98.

50. Youden WJ. Index for rating diagnostic tests. Cancer. 1950;3:32-5.

51. Rami L, Molinuevo JL, Sanchez-Valle R, Bosch B, Villar A. Screening for amnestic mild cognitive impairment and early Alzheimer's disease with M@T (Memory Alteration Test) in the primary care population. Int J Geriatr Psychiatry. 2007;22:294-304.

52. Carnero-Pardo C, Espejo-Martinez B, Lopez-Alcalde S, Espinosa-Garcia M, Saez-Zea C, Vilchez-Carrillo R, Hernandez-Torres E, Navarro-Espigares JL. Effectiveness and costs of phototest in dementia and cognitive impairment screening. BMC Neurol. 2011;11:92.

53. Takechi H, Dodge HH. Scenery Picture Memory Test: a new type of quick and effective screening test to detect early stage Alzheimer's disease patients. Geriatr Gerontol Int. 2010;10:183-90.
54. Brooke P, Bullock R. Validation of a 6 item cognitive impairment test with a view to primary care usage. Int J Geriatr Psychiatry. 1999; 14(January):936-40

55. Brodaty H, Pond D, Kemp NM, Luscombe G, Harding L, Berman K, Huppert Fa. The GPCOG: a new screening test for dementia designed for general practice. J Am Geriatr Soc. 2002:50:530-4.

56. Borson S, Scanlan J, Brush M, Vitaliano P, Dokmak A. The mini-cog: a cognitive "vital signs" measure for dementia screening in multi-lingual elderly. Int J Geriatr Psychiatry. 2000;15:1021-7.

57. Inouye SK, Robison JT, Froehlich TE, Richardson ED. The time and change test: a simple screening test for dementia. J Gerontol A Biol Sci Med Sci. 1998;53:M281-6.

58. Podsiadlo D, Richardson S. The timed "Up \& Go": a test of basic functional mobility for frail elderly persons. J Am Geriatr Soc. 1991;39:142-8.

59. Richards M, Marder K, Bell K, Dooneief G, Mayeux R, Stern Y. Interrater reliability of extrapyramidal signs in a group assessed for dementia. Arch Neurol. 1991:48:1147-9.

60. Hummel T, Sekinger B, Wolf SR, Pauli E, Kobal G. "Sniffin" Sticks': Olfactory performance assessed by the combined testing of odour identification, odor discrimination and olfactory threshold. Chem Senses. 1997:22:39-52.

61. Hummel T, Kobal G, Gudziol H, Mackay-Sim A. Normative data for the "Sniffin' Sticks" including tests of odor identification, odor discrimination, and olfactory thresholds: an upgrade based on a group of more than 3000 subjects. Eur Arch Otorhinolaryngol. 2007;264:237-43.

62. Pfeffer Rl, Kurosaki TT, Harrah $\mathrm{CH}$, Chance JM, Filos S. Measurement of functional activities in older adults in the community. J Gerontol. 1982; 37:323-9.

63. Lawton MP, Brody EM. Assessment of older people: self-maintaining and instrumental activities of daily living. Gerontologist. 1969:9:179-86.

64. Katz S, Ford AB, Moskowitz RW, Jackson BA, Jaffe MW. Studies of Illness in the Aged. The Index of ADL: A Standardized Measure of Biological and Psychosocial Function. JAMA. 1963;185:914-9.

65. Galvin JE, Roe CM, Powlishta KK, Coats MA, Muich SJ, Grant E, Miller JP, Storandt M, Morris JC. The AD8: a brief informant interview to detect dementia. Neurology. 2005;65:559-64.

66. Tsoi KKF, Chan JYC, Hirai HW, Wong SYS, Kwok TCY. Cognitive tests to detect Dementia. JAMA Intern Med. 2015:175(9):1450-8. doi:10.1001/ jamainternmed.2015.2152.

67. Buschke H, Kuslansky G, Katz M, Stewart WF, Sliwinski MJ, Eckholdt HM, Lipton RB. Screening for dementia with the memory impairment screen Neurology. 1999:52:231-8.

68. Hodkinson HM. Evaluation of a mental test score for assessment of mental impairment in the elderly. Age Ageing. 1972;1:233-8.

69. About The Licenses - Creative Commons [http://creativecommons.org/ licenses/].

70. Hsieh S, Schubert S, Hoon C, Mioshi E, Hodges JR. Validation of the Addenbrooke's cognitive examination III in frontotemporal dementia and Alzheimer's disease. Dement Geriatr Cogn Disord. 2013;36:242-50.

71. Adshead F, Cody DD, Pitt B. BASDEC: a novel screening instrument for depression in elderly medical inpatients. BMJ. 1992:305:397.

72. Bucks RS, Ashworth DL, Wilcock GK, Siegfried K. Assessment of activities of daily living in dementia: development of the Bristol Activities of Daily Living Scale. Age Ageing. 1996;25:113-20.

73. Bertens LCM, van Mourik Y, Rutten FH, Cramer M-JM, Lammers J-WJ, Hoes AW, Reitsma JB, Moons KGM. Staged decision making was an attractive alternative to a plenary approach in panel diagnosis as reference standard. J Clin Epidemiol. 2015;68(4):418-25. doi:10.1016/j.jclinepi.2014.09.020.

74. Erkinjuntti T, Ostbye T, Steenhuis R, Haschinski V. The effect of different diagnostic criteria on the prevalence of dementia. N Engl J Med. 1997;337: 1667-74.

75. Flahault A, Cadilhac M, Thomas G. Sample size calculation should be performed for design accuracy in diagnostic test studies. J Clin Epidemiol. 2005:58:859-62.

76. Wind AW, Van Staveren G, Schellevis FG, Jonker C, van Eijk JTM. The validity of the judgement of general practitioners on dementia. Int J Geriatr Psychiatry. 1994;9:543-9.

77. Vittinghoff $E$, McCulloch CE. Relaxing the rule of ten events per variable in logistic and Cox regression. Am J Epidemiol. 2007;165:710-8.

78. Hosmer DW, Lemesbow S. Goodness of fit tests for the multiple logistic regression model. Commun Stat Methods. 1980;9:1043-69. 
79. Steyerberg EW, Vickers AJ, Cook NR, Gerds T, Gonen M, Obuchowski N, Pencina MJ, Kattan MW. Assessing the performance of prediction models: a framework for traditional and novel measures. Epidemiology. 2010;21:128-38.

80. van Buuren S. Multiple imputation of discrete and continuous data by fully conditional specification. Stat Methods Med Res. 2007;16:219-42.

81. White IR, Royston P, Wood AM. Multiple imputation using chained equations: Issues and guidance for practice. Stat Med. 2011;30:377-99.

82. Steyerberg EW, Harrell FE, Borsboom GJ, Eijkemans MJ, Vergouwe Y, Habbema JD. Internal validation of predictive models: efficiency of some procedures for logistic regression analysis. J Clin Epidemiol. 2001;54:774-81.

Submit your next manuscript to BioMed Central and we will help you at every step:

- We accept pre-submission inquiries

- Our selector tool helps you to find the most relevant journal

- We provide round the clock customer support

- Convenient online submission

- Thorough peer review

- Inclusion in PubMed and all major indexing services

- Maximum visibility for your research

Submit your manuscript at www.biomedcentral.com/submit 